\title{
1 The past, present and future of organizational routines: introduction to the Handbook of Organizational Routines Markus C. Becker
}

To understand routines is to understand organizations. ${ }^{1}$ Routines are ubiquitous in organizations, and an integral part of organizations. One is hard put to identify an organization where no routines are present. A large part of the tasks carried out in organizations, such as manufacturing, marketing and selling goods and services, are accomplished in routinized ways. This is not only true for trivial operations, such as manufacturing, but also pervades processes such as decision making, strategizing or even change and innovation. Organizational routines are the building blocks of organizations: they capture the typical ways in which organizations accomplish their tasks.

As it turns out, understanding organizational routines is not a trivial undertaking. So far, just getting an overview of the concept of organizational routines and what we know about organizational routines was quite difficult. For one, no obvious point of reference was available, the 1996 Industrial and Corporate Change article documenting the discussion of the Santa Fe group perhaps being the only exception (Cohen et al., 1996). The Handbook of Organizational Routines addresses this gap.

In this introduction, I will not attempt to describe comprehensively the present state of the research on organizational routines. As James March (1965: ix) so eloquently put it, 'no editor, and least of all a sympathetic one, should attempt to summarize that state. It is what it is; and what it is can best be discovered by reading the detailed chapters'. Rather, I want to use the occasion to sketch an overarching framework for the chapters in this volume, and highlight some threads that link them in ways that are not always obvious from the individual chapters themselves. The Handbook is structured around four topics, corresponding to its four sections. Each mirrors an important set of questions in the literature on organizational routines.

\section{The concept of organizational routines}

A recurrent theme in articles on organizational routines in the past was the definitional ambiguity surrounding the concept. For obvious reasons, this 
is no attractive feature, neither of the concept nor of the literature that deals with it. The Handbook bears good news on the issue. For starters, a cause of ambiguity in definitions has now become clear. On this basis, scholars have subsequently pointed out several ways to move forward. In my reading, when scholars have used the term 'organizational routine', they have referred to three different concepts: recurrent behaviour patterns, rules or procedures, and dispositions (for a detailed review of the literature, see Becker, 2004). At the same time, routines are ubiquitous in organizations, and the term has an everyday, commonsense meaning. Against this backdrop, it does not come as much of a surprise that the term 'routine' has been linked to a set of different (albeit related) concepts. What to make of it? The three concepts clearly cannot be reduced to one or the other. Rules are not behaviour, behaviour is not the same as rules, potential behaviour is not the same as actual behaviour, and so on. This might indicate that the underlying constructs the terms refer to might also be irreducible to one another. This question clearly lies beyond the scope of this introduction. It does, however, hint at the relations between rules, behaviour and disposition as fruitful foci of description and analysis. How do rules relate to recurrent behaviour patterns? How do dispositions relate to recurrent behaviour patterns? Answering these questions is important for understanding organizations. Acknowledging that scholars link the term 'routines' to three different concepts that are related but different holds the key to unlocking the potential of the routines concept to inform research questions on organizations. The way ahead is to consider the contribution each of those concepts, and their interactions, interrelations and interdependencies, bring to such research questions.

One more immediate question remains, however: what does - and should - the term 'organizational routines' refer to? In the Handbook, this question is tackled from two angles. In his entry, 'The concept of a routine', Geoffrey M. Hodgson approaches the question by picking up the distinction of potentiality and actuality. From this perspective, the three constructs that authors have referred to fall into two groups: recurrent behaviour patterns (actualized, realized), and rules and procedures, and dispositions (both describing potential behaviour). Using this distinction, Hodgson concludes that one term cannot usefully denote both potentiality and actuality. He argues that the term 'organizational routines' should refer to potential behaviour - causes of stable behaviour patterns - rather than to actual behaviour that has been expressed. In 'Organizational routines in evolutionary theory', Thorbjørn Knudsen considers the question from a different angle, garnering support for a similar conclusion from different quarters. He asks: 'What characteristics does the concept of organizational routines need to have in order to answer the questions it is supposed to 
answer?' Economic (and organizational) change is the most prominent question to which the organizational routines concept is seen to provide an answer. Famously, Nelson and Winter's (1982) idea of routines as equivalent of genes proposes one possible explanatory avenue. Precisely what characteristics, however, would the concept of routines need to have in order to fulfil the role of 'equivalent to the gene' in evolutionary theories of cultural and economic change? Importantly for the definition of routines, Knudsen's answer is that, to fulfil such a role, organizational routines need to be defined as causes of behaviour (more specifically, as dispositions), rather than behaviour patterns. ${ }^{2}$

Looking ahead, these insights suggest three issues on which it appears fruitful to adapt our thinking. First, to use the label 'routines' for only one of these three concepts, and other labels for the others (while not denying all three are important in explaining certain phenomena). Second, to take note of powerful arguments as to why organizational routines should refer to dispositions: amongst others, it seems that only if understood as dispositions can we expect routines to do the explanatory work that has always been their promise. Third, to unpack the potential that lies in recognizing there are three different concepts that seem to be linked. The potential is to explore (systematic) interactions between these three concepts. This could open a potential explanatory avenue for phenomena of great importance to understanding organizations, such as their stability and change. The tide is thus turning. Definitional ambiguity is giving way to clearly outlined paths for tackling important research questions on organizations.

\section{Organizational routines across different fields}

The concept of organizational routines has a number of particular features that should make it very attractive for many fields of the social sciences. The first comes out clearly if we consider the concept of organizational routines as a part of the family of concepts such as institutions, norms or conventions. All these concepts refer to the collective level. The concept of organizational routines is the most micro-level concept amongst these collective-level concepts. Thus, it seems particularly well-suited for capturing collective action below the level of the organization as a whole, such as collective action encompassing only a fraction of the organization's members as in a team or group.

The second feature of the organizational routines concept that sets it apart from other, collective-level concepts is to relate the individual level to the collective level. Organizational routines capture stable structures in collective action that emerge from the interrelating of individual action. Such individual action can itself be patterned in stable ways, as expressed by the individual-level concept of habit. Habits can be building blocks of 
organizational routines. This idea can be found in the works of, for instance, Dewey (Cohen, 2007), but also other pragmatist authors such as C.S. Peirce. The feature of relating the individual level to the collective level has another powerful implication: it means that, by nature, the concept of organizational routine is neither over- nor undersocialized, to use Granovetterian terminology (Granovetter, 1985). Precisely because the concept of organizational routines relates individual to collective behaviour, abstracting from individual action that is intertwined into collective patterns of action would leave out an important part of what organizational routines are supposed to capture. It would result in omitting an important part of organizational routines. The same would result from attempting to reduce the pattern of interlocked actions of individuals to the individual level only. In so doing, one would lose sight of the pattern (and of its performance implications). Furthermore, there is an even stronger reason why the organizational routines concept is neither over- nor undersocialized. To interlock individual action seems to require orienting one's actions towards others. The empirical studies of organizational routines by Karl Weick and co-workers (Weick, 1990; Weick and Roberts, 1993) forcefully establish the importance of orienting oneself towards triggers and cues by other team members, in order to generate a smooth and wellfunctioning routine that will remain stable even under extreme pressure. ${ }^{3}$ The interlocking of individual actions into collective-level routines seems crucial. Trying to reduce organizational routines exclusively to the collective or the individual level would sideline one of its crucial characteristics.

In this context, it is interesting to note that the concept of organizational routines can be seen as a concept of order. Going back to Weber, the concept of order refers to "a prescription for how to act, that is "exemplary" or "obligatory"' (Weber, 1978: 311, cf. Knudsen and Swedberg, 2007: 16). ${ }^{4}$ Many other concepts of order exist, such as institution, convention, norm, tradition, folkways or mores. All of them have been applied to the sphere of the economy (even the notion of folkways: see Ellsworth's (1952) 'factory folkways'). There are many differences between these concepts, and to consider them is beyond the scope of this chapter. What is similar across all these concepts of order is that they generate more or less stable links between situations and behavioural options. When facing a particular situation, the actor is likely to choose a particular behavioural option. In this respect, orders have a similar effect to what James March (1994) calls the 'logic of appropriateness'. It answers the question, 'What does a person such as I, or an organization such as this, do in a situation such as this?' Such appropriateness also generates more or less stable links between situations and behavioural options. ${ }^{5}$ All concepts of order guide actors towards more or less stable links between situations and behavioural options. 
Institutions, conventions, norms, traditions, folkways and mores do so in different ways, for instance through sanctions (in the case of norms). Orders all increase the probability that actors will respond to a certain (trigger in a) situation with a particular action, rather than other actions. Concepts of order link situations to behaviour. By so doing, they structure individual behaviour.

Orders play important roles in all fields of the social sciences. The concept of organizational routines has not received much attention outside the field of, broadly speaking, management and business, and economics. One reason is that each field of the social sciences has a 'primary' concept of order that has absorbed most of the fields' attention, such as institutions in sociology. It certainly makes sense to focus on a concept of order that is aligned with the level of analysis of the field. Organizational routines allow us to capture order below the level of the organization and, thus, to describe building blocks of structured behaviour that the organization's behaviour is made up of.

Organizations are omnipresent in modern society (Simon, 1991). They pervade (almost) all aspects of social life, and all fields of the social sciences. Adding additional analytical power on the organizational level should be in the interest of theories in all fields of the social sciences. The chapters in this section take stock of the reception of the concept of organizational routines in a number of fields of the social sciences.

In his chapter, 'Organizational routines in political science', Timothy McKeown presents an overview of the political science literature, which shares an interest in phenomena such as administrative organizations and bureaucracies with the literature interested in organizational routines. As he explains, the political science literature has used the notion of organizational routines for analysing issues such as bureaucracies, administration and government conduct. He describes the historical trajectory of studies of routines within political science, tracing the interpretations of routines as patterned behaviour and as rules and how they have allowed us to analyse problems in political science. McKeown's article identifies docking points and potential synergies between political science and studies of organizations. In doing so, he goes beyond identifying obvious points of contact such as bureaucratic formalization and points to areas of fruitful cooperation between the fields.

Sociology is, of course, another discipline that should have a strong shared interest in organizational routines, yet, for many non-sociologists, it is not easy to leverage the sociology literature for adding to their understanding of organizational routines. In the article 'Routines, 'going concerns' and innovation: towards an evolutionary economic sociology', Marc Ventresca and William Kaghan build a bridge. In their chapter, they 
guide non-sociologists through micro- and macro-sociological approaches, carefully pointing out how they can be linked up with the concept of organizational routines and the literature on it. They review work from organizational and economic sociology that focuses on the relationship between routines and organizational and institutional innovation. In their article, Ventresca and Kaghan identify docking points between the management literature on organizational routines and the sociological literature and foster transfer of ideas between the two fields. Moreover, they outline a sociological view of routines that relates organizational stability to organizational change and that forms the basis for a 'theory of the innovative firm', and identify some elements of an evolutionary economic sociology.

John Burns and Robert Scapens's chapter on 'Organizational routines in accounting' describes how scholars within the accounting discipline have developed an understanding of its subject through conceptualizing accounting routines, and how accounting might contribute towards developing our understanding of organizational routines literature. In accounting, formalized rules obviously have a particularly important role. Linking back to the relation between rules, behaviour patterns and dispositions mentioned at the beginning, accounting therefore presents a particularly good occasion for research on the interaction between rules and behaviour patterns. Burns and Scapens offer an insightful discussion of this interaction. Let me point out a curious coincidence that perhaps is more than just accidental: their analysis of the transmission of routines in the specific context of accounting bears an interesting resemblance to recent conceptual work on evolutionary theory in the social realm (Knudsen, 2002: 450). The authors have arrived at this argument by different routes (empirical description in accounting and theoretical argument) and, apparently, without being aware of each other's work. This is an encouraging sign because it signals convergence between empirical research in specific fields and conceptual research anchored in disciplinary arguments.

Organizational routines are often seen in connection with competences and capabilities, usually considered the building blocks of the latter (Dosi et al., 2000). Largely because of this connection, organizational routines also have a role in the strategy literature. The chapter on 'Problem solving and governance in the capability-based view of the firm: the roles and theoretical representation of organizational routines', by Giovanni Dosi, Marco Faillo and Luigi Marengo provides a detailed overview of the relationship between the notion of organizational routines and the capabilitybased view of the firm, a particular instance of the resource-based view of strategy (Barney, 1991; Peteraf, 1993). A special focus in that overview is on the double function of routines as both problem-solving arrangements and governance devices, and on recent efforts to formalize the processes of 
search and organizational adaptation, in which routines emerge and are stabilized. The chapter provides an overview of such efforts, including NK models (Kauffman, 1993). By broaching the topic of search, the chapter provides a link to the following section, on 'Organizational routines, search and learning'.

\section{Organizational routines, search and learning}

Part III turns to some of the key issues that organizational routines can help understand better. Some readers might be surprised to see organizational routines associated with 'dynamic' topics such as search and learning. Are organizational routines not linked, rather, to stability or rigidity? The answer is 'yes and no'. Yes, because organizational routines can be sources of stability in organizations (Schulz, this volume). No, because, at the same time, organizational routines can also be sources of organizational change, for instance, through learning and search. In a series of articles, Martha Feldman (2000; 2003; Feldman and Pentland, 2003) recently explained how organizational routines are endogenous drivers of organizational change (see also Knudsen, this volume). Learning and search are some of the key processes by which such change is generated (Miner et al., this volume; Greve, this volume). Organizational routines have crucial roles in these processes. Part III is devoted to identifying the role of organizational routines in learning, search and adaptation processes, thereby tightening our grasp of when and how organizational routines can drive change. Keeping in mind that organizational routines can be the source both of stability and of change, it should be clear why the topics dealt with in Part III are crucial: to understand when and how organizational routines fuel stability, and when and how they fuel change.

The analytical power of organizational routines in understanding incremental organizational change represents one of the most important potentials of the organizational routines concept. Martha Feldman (2000; 2003; Feldman and Pentland, 2003) changed the way we understand routines when she explained how organizational routines can be endogenous drivers of organizational change - a far cry from the idea of organizational routines as the opposite of organizational change that is so widely diffused. If one accepts this idea, the chapters in this section open the door to coming to grips with understanding the role of organizational routines in bringing about organizational change.

While the other entries in this section focus on one particular instance of change, Thorbjørn Knudsen's chapter on 'Organizational routines in evolutionary theory' considers the role of organizational routines in evolutionary theories of cultural and economic change. He identifies features of organizational routines that account for their role in such theories, and 
characteristics that every evolving unit needs to have in an evolutionary theory. Nelson and Winter's (1982) notion of 'routines as genes' has turned out to be most inspiring to many scholars. It has also turned out difficult to understand, and not easily applied in further research. For the first time, Knudsen's chapter presents a full-fledged analysis of the role of routines in evolutionary theories of cultural and economic change, a helpful endeavour for all who grapple with applying Nelson and Winter's (1982) inspiring idea.

In their chapter, 'Organizational routines and organizational learning', Anne S. Miner, Michael Ciuchta and Yan Gong provide an overarching framework that demonstrates how organizational learning processes that involve routines can encapsulate many of the sub-processes described elsewhere in this part of the Handbook. Numerous empirical findings that substantiate the model are presented. The authors first note that routines can form the basis of organizational memory, thus providing a source of stability in organizations discussed by Schulz (this volume). Miner et al. then establish that a variation-selection-retention model can be used to account for both deliberate and emergent learning processes involving routines. Notably, the performance feedback learning processes discussed by Greve (this volume) are a special case of the selection process found within the broader variation-selection-retention perspective. The authors also note that, although much empirical research has viewed routines as stable with the change in the mix of routines as evidence of organizational learning, more attention is now being directed towards the concept that change in routines themselves can be engines of learning (Miner, Ciuchta and Gong, this volume). This more contemporary understanding of the role that routines play in organizational learning provides needed insights into the emergence of routines (Lazaric, this volume). Lastly, the authors tackle an understudied organizational process by exploring how specific routines can be deployed to generate learning.

In the management literature, search processes are amongst the most important explanations of change (Cyert and March, 1963). In such processes, performance feedback plays a crucial role. Measured against an aspiration level, it triggers search when results are below the aspiration level (in case of slack, extra resources trigger search). In the entry 'Organizational routines and performance feedback', Henrich Greve analyses the role of routines in this important step of search processes and, thus, the role of routines in what is the perhaps most widely diffused explanation of organizational change. Many papers on search have focused on either the macro or micro level. In his chapter, Greve treads more or less unchartered territory in exploring the meso level. Moreover, he covers the multi-level nature of performance feedback effects on routines, that is, performance feedback 
operating on the organization, on work groups in the organization, and on individuals, with differing goals and consequences.

The objective of Nathalie Lazaric's chapter on 'Routines and routinization: an exploration of some micro-cognitive foundations' is to provide a framework for examining changes occurring within organizational routines. For doing so, she casts light on the cognitive micro foundations of routines in order to understand the drivers and triggers of the routinization process. Establishing the link between organizational routines and procedural memory (Cohen and Bacdayan, 1994), she then explores how individual and collective memorization occurs, in order to grasp how knowledge can be converted into routines.

'Staying on track: a voyage to the internal mechanisms of routine reproduction', by Martin Schulz, focuses on the stability of routines and its sources. Organizational routines are sources of stability and, thus, core concepts in theories of social and economic order. What mechanism endogenous to routines generates such stability? If their stabilizing effect could be reduced to external forces, we would not need a concept of routine. Schulz reviews mechanisms that address how prior actions select consecutive action, and how the mechanisms coevolve with routines. The mechanisms cover, amongst others, habitualization, priming, institutionalization, value infusion, formalization, artefacts, calculation and competency traps.

The chapter on 'The role of teams and communities in the emergence of organizational routines', by Patrick Cohendet and Patrick Llerena, considers how routines emerge. The authors elaborate on the well-established feature of context-dependency of organizational routines, exploring teams and communities as two different contexts in which routines emerge and develop. In so doing, they also cast light on two aspects that have often received less attention than deemed appropriate, that is, the nature of the group of agents involved in the routine (cf. Feldman, 2000), and the cognitive, motivational and incentive aspects of organizational routines (cf. Coriat and Dosi, 1998).

\section{Conducting empirical research on organizational routines}

The final Part shifts to considering how to apply the concept of organizational routines in empirical research. Empirical research will play an important role in casting light on organizational phenomena. So far, however, employing the concept of organizational routines in empirical research has turned out to be somewhat difficult. Qualitative studies have lacked cumulativeness, partly due to different definitions of organizational routines that authors have used. Moreover, different definitions have often led to different operationalizations (for instance in surveys). The authors of the two chapters in this part share their rich experience on how to carry out 
empirical research on organizational routines. This final part covers qualitative, quantitative and experimental methods, providing inputs on all the drawers in the methodological toolbox.

In 'Issues in empirical field studies of organizational routines', Brian Pentland and Martha Feldman cover qualitative and quantitative methods for research on organizational routines. Focusing on the two tasks of identification and comparison, they elaborate on a set of issues involved in these two tasks. They also offer practical advice, based on their own empirical research. Regarding identification, they discuss ostensive and performative aspects of routines, as well as artefacts (such as written standard operating procedures), their relationship and how to identify each in practice. As regards comparison, they discuss details of quantitative methods for comparing the similarity of behaviour sequences, an issue pioneered by one of the authors.

In the chapter on 'Conducting experimental research on organizational routines', Alessandro Narduzzo and Massimo Warglien review experimental research related to the concepts of routine and routinization, and explore some opportunities for dialogue with the recent work in experimental economics and behavioural game theory. In so doing, they identify some features of organizational routines that are amenable to experimental inquiry, focusing on issues of procedural memory, how routines are retrieved, the implications of routinization for information search, suboptimality and path dependency. They argue that many experimental game settings provide interesting grounds for the emergence of routinized behaviour, even though the classical paradigm within which experiments on learning in games are developed seems too narrow for understanding the development of routines. They suggest how experimental practices on games might be oriented to further the dialogue between experimental research, and point out what insights there are in behavioural game theory for students of routines.

\section{Conclusion and outlook}

As a research topic, organizational routines have quite particular features. They are ubiquitous, everyone has an intuitive idea of what they are, and they seem taken for granted and difficult to trace in empirical research. Moreover, when we want to use the concept, it often turns out more difficult than expected. It would be a mistake, however, to resign and leave off at this point. Much progress on clarifying the concept of routines, and how it can be used in empirical research, has been made over the last couple of years. Different methodologies for empirical research on organizational routines have been pioneered, described and tested. They cover quantitative, qualitative and experimental methods. By now, templates are increasingly available - and being applied - for carrying out quantitative, qualitative and 
experimental research on organizational routines. This is a big step forward. An increasing number of empirical studies on organizational phenomena, applying organization routines as an analytical lens, are now carried out. The results are starting to cumulate (for instance, articles applying Pentland-style sequence analysis). More elaborate methodologies are being developed and consolidated. At the same time, the concept has also been sharpened. Another encouraging sign is worth noting: for making advances in understanding empirical phenomena, it seems helpful to draw both on empirical research and on research firmly rooted in conceptual frameworks in the scientific disciplines. This also holds for advancing research on organizations (Heath and Sitkin, 2001). It is encouraging to see this is feasible and actually being done in the case of organizational routines. We have actually broached the task of drawing on underlying disciplinary knowledge in doing research on organizations by using the concept of organizational routines. In this light, the fact that much still remains to be done signals there is much unused potential still to be reaped. These are all promising signs that bode well for the potential of applying the concept of organizational routines in research on understanding organizations.

\section{Notes}

1. Thanks to Thorbjørn Knudsen, Anne Miner, Nils Stieglitz and Francesco Zirpoli for helpful comments on earlier versions of this draft. This introduction has also benefited from discussions of related topics with Michael Cohen, Brian Pentland and Richard Swedberg. All remaining errors and omissions are my own. Support from the Agence Nationale de Recherche, France, is gratefully acknowledged ('Jeunes Chercheuses et Jeunes Chercheurs' program, grant no. JC05-44029).

2. The careful reader will note that authors of the different chapters use different interpretations of the term 'organizational routines'. In all chapters, authors clearly identify their definitions in order to help the reader. The variety of interpretations of the term reflects the current state of the field. It is one thing to argue what should be and another to actually reach that state. As pointed out in this introduction, there are promising signs of convergence.

3. The notion of 'mindfulness' that empirical research on organizational routines such as Weick's has identified provides a bridge to the 'orientation towards others' in Weber. 'Mindfulness' points to attention, and 'orientation' to how it is directed or on what it is focused. Links to the 'focus of attention' in the Behavioral Theory of the Firm are obvious.

4. In the sphere of the (capitalist) economy, the concept of order refers to a 'general prescription for how to act in the sphere of the economy, with the purpose of making a profit' (Knudsen and Swedberg, 2007: 16).

5. The stability of such links can be usefully described as conditional probability (Knudsen, this volume).

\section{References}

Barney, Jay (1991), 'Firm resources and sustained competitive advantage', Journal of Management, 17(1), 99-120.

Becker, Markus C. (2004), 'Organizational routines: a review of the literature', Industrial and Corporate Change, 13(4), 643-77.

Cohen, Michael D. (2007), 'Reading Dewey: reflections on the study of routine', Organization Studies, 28(5), 773-86. 


\section{Handbook of organizational routines}

Cohen, Michael and Paul Bacdayan (1994), 'Organizational routines are stored as procedural memory: evidence from a laboratory study', Organization Science, 5(4), 554-68.

Cohen, Michael D., Roger Burkhart, Giovanni Dosi, Massimo Egidi, Luigi Marengo, Massimo Warglien and Sidney G. Winter (1996), 'Routines and other recurring action patterns of organizations: contemporary research issues', Industrial and Corporate Change, 5(3), 653-98.

Coriat, Benjamin and Giovanni Dosi (1998), 'Learning how to govern and learning how to solve problems: on the co-evolution of competences, conflicts and organizational routines', in Alfred D. Chandler, Jr., Peter Hagström and Örjan Sölvell (eds), The Dynamic Firm. The Role of Technology, Strategy, Organization and Regions, Oxford: Oxford University Press, pp. 103-133.

Cyert, Richard M. and James G. March (1963/1992), A Behavioral Theory of the Firm, 2nd edn, Oxford: Blackwell.

Dosi, Giovanni, Richard R. Nelson and Sidney G. Winter (2000), 'Introduction: the nature and dynamics of organizational capabilities' in Giovanni Dosi, Richard R. Nelson and Sidney G. Winter (eds), The Nature and Dynamics of Organizational Capabilities, Oxford: Oxford University Press, pp. 1-22.

Ellsworth, John S. (1952), Factory Folkways - A Study of Institutional Structure and Change, New Haven, CT: Yale University Press.

Feldman, Martha S. (2000), 'Organizational routines as a source of continuous change', Organization Science, 11(6), 611-29.

Feldman, Martha S. (2003), 'A performative perspective on stability and change in organizational routines', Industrial and Corporate Change, 12(4), 727-52.

Feldman, Martha S. and Brian T. Pentland (2003), 'Reconceptualizing organizational routines as a source of flexibility and change', Administrative Science Quarterly, 48(1), 94-118.

Granovetter, Mark (1985),' 'Economic action and social structure: the problem of embeddedness', American Journal of Sociology, 9(3), 481-510.

Heath, Chip and Sim B. Sitkin (2001), 'Big-B versus big-O: what is organizational about organizational behavior?', Journal of Organizational Behavior, 22, 43-58.

Kauffman, S.A. (1993), The Origins of Order, New York: Oxford University Press.

Knudsen, Thorbjørn (2002), 'Economic selection theory', Journal of Evolutionary Economics, 12, 443-70.

Knudsen, Thorbjørn and Richard Swedberg (2007), 'Capitalist entrepreneurship: making profit through the unmaking of economic orders', paper presented at the Conference on Capitalism and Entrepreneurship, Center for the Study of Economy and Society, Cornell University, 28-29 September.

March, James G. (1965), 'Introduction', in James G. March (ed.), Handbook of Organizations, Chicago, IL: Rand McNally, pp. ix-xvi.

March, James G. (1994), A Primer on Decision Making - How Decisions Happen, New York: The Free Press.

Nelson, Richard R. and Sidney G. Winter (1982), An Evolutionary Theory of Economic Change, Cambridge, MA: Harvard University Press.

Peteraf, Margaret A. (1993), 'The cornerstone of competitive advantage: a resource-based view', Strategic Management Journal, 14, 179-88.

Simon, Herbert A. (1991), 'Organizations and markets', Journal of Economic Perspectives, 5(2), 25-44.

Weber, Max (1978), Economy and Society, Guenther Roth and Claus Wittich (eds), Berkeley and Los Angeles: University of California Press.

Weick, Karl E. (1990), 'The vulnerable system: an analysis of the Tenerife air disaster', Journal of Management, 16(3), 571-93.

Weick, Karl E. and Roberts, Karlene H. (1993), 'Collective mind in organizations: heedful interrelating on flight decks', Administrative Science Quarterly, 38, 357-81. 